\title{
On fixed points of $\alpha-\psi$-contractive multifunctions
}

\author{
J Hasanzade Asl', S Rezapour ${ }^{1,2}$ and N Shahzad ${ }^{3 *}$
}

${ }^{\text {*Correspondence: }}$

nshahzad@kau.edu.sa

${ }^{3}$ Department of Mathematics, King Abdulaziz University, P.O. Box 80203

Jeddah, 21859, Saudi Arabia

Full list of author information is

available at the end of the article

\begin{abstract}
Recently Samet, Vetro and Vetro introduced the notion of $\alpha$ - $\psi$-contractive type mappings and established some fixed point theorems in complete metric spaces. In this paper, we introduce the notion of $\alpha_{*}-\psi$-contractive multifunctions and give a fixed point result for these multifunctions. We also obtain a fixed point result for self-maps in complete metric spaces satisfying a contractive condition.
\end{abstract}

Keywords: $\alpha_{*}-\psi$-contractive multifunction; fixed point; partial metric

\section{Introduction}

Fixed point theory has many applications in different branches of science. During the last few decades, there has been a lot of activity in this area and several well-known fixed point theorems have been extended by a number of authors in different directions (see, for example, [1-38]). Recently Samet, Vetro and Vetro introduced the notion of $\alpha$ - $\psi$-contractive type mappings [33]. Denote with $\Psi$ the family of nondecreasing functions $\psi:[0, \infty) \rightarrow[0, \infty)$ such that $\sum_{n=1}^{\infty} \psi^{n}(t)<\infty$ for all $t>0$, where $\psi^{n}$ is the $n$th iterate of $\psi$. It is known that $\psi(t)<t$ for all $t>0$ and $\psi \in \Psi$ [33]. Let $(X, d)$ be a metric space, $T$ be a self-map on $X, \psi \in \Psi$ and $\alpha: X \times X \rightarrow[0, \infty)$ be a function. Then $T$ is called an $\alpha$ - $\psi$-contraction mapping whenever $\alpha(x, y) d(T x, T y) \leq \psi(d(x, y))$ for all $x, y \in X$. Also, we say that $T$ is $\alpha$-admissible whenever $\alpha(x, y) \geq 1$ implies $\alpha(T x, T y) \geq 1$ [33]. Also, we say that $\alpha$ has the property (B) if $\left\{x_{n}\right\}$ is a sequence in $X$ such that $\alpha\left(x_{n}, x_{n+1}\right) \geq 1$ for all $n \geq 1$ and $x_{n} \rightarrow x$, then $\alpha\left(x_{n}, x\right) \geq 1$ for all $n \geq 1$. Let $(X, d)$ be a complete metric space and $T$ be an $\alpha$-admissible $\alpha$ - $\psi$-contractive mapping on $X$. Suppose that there exists $x_{0} \in X$ such that $\alpha\left(x_{0}, T x_{0}\right) \geq 1$. If $T$ is continuous or $T$ has the property (B), then $T$ has a fixed point (see [33]; Theorems 2.1 and 2.2). Finally, we say that $X$ has the property $(\mathrm{H})$ whenever for each $x, y \in X$ there exists $z \in X$ such that $\alpha(x, z) \geq 1$ and $\alpha(y, z) \geq 1$. If $X$ has the property $(\mathrm{H})$ in Theorems 2.1 and 2.2, then $X$ has a unique fixed point ([33]; Theorem 2.3). It is considerable that the results of Samet et al. generalize similar ordered results in the literature (see the results of the third section in [33]). The aim of this paper is to introduce the notion of $\alpha_{*}-\psi$-contractive multifunctions and give a fixed point result about the multifunctions. Let $(X, d)$ be a metric space, $T: X \rightarrow 2^{X}$ be a closed-valued multifunction, $\psi \in \Psi$ and $\alpha: X \times X \rightarrow[0, \infty)$ be a function. In this case, we say that $T$ is an $\alpha_{*}-\psi$-contractive multifunction whenever $\alpha_{*}(T x, T y) H(T x, T y) \leq \psi(d(x, y))$ for $x, y \in X$, where $H$ is the Hausdorff generalized metric, $\alpha_{*}(A, B)=\inf \{\alpha(a, b): a \in A, b \in B\}$ and $2^{X}$ denotes the family of all nonempty subsets of $X$. Also, we say that $T$ is $\alpha_{*}$-admissible whenever $\alpha(x, y) \geq 1$ implies $\alpha_{*}(T x, T y) \geq 1$.

@ 2012 Asl et al.; licensee Springer. This is an Open Access article distributed under the terms of the Creative Commons Attribution License (http://creativecommons.org/licenses/by/2.0), which permits unrestricted use, distribution, and reproduction in any medium, provided the original work is properly cited. 
Example 1.1 Let $X=[0, \infty), d(x, y)=|x-y|$ and $\delta \in(0,1)$ be a fixed number. Define $T$ : $X \rightarrow 2^{X}$ by $T x=[0, \delta x]$ for all $x \in X$ and $\alpha: X \times X \rightarrow[0, \infty)$ by $\alpha(x, y)=1$ whenever $x, y \in$ $[0,1]$ and $\alpha(x, y)=0$ whenever $x \notin[0,1]$ or $y \notin[0,1]$. Now, we show that $T$ is $\alpha_{*}$-admissible. If $\alpha(x, y) \geq 1$, then $x, y \in[0,1]$ and so $T x$ and Ty are subsets of $[0,1]$. Thus, $a, b \in[0,1]$ for all $a \in T x$ and $b \in T y$. Hence, $\alpha(a, b)=1$ for all $a \in T x$ and $b \in T y$. This implies that

$$
\alpha_{*}(T x, T y)=\inf \{\alpha(a, b): a \in T x, b \in T y\}=1 .
$$

Therefore, $T$ is $\alpha_{*}$-admissible. Now, we show that $T$ is an $\alpha_{*}-\psi$-contractive multifunction, where $\psi(t)=\delta t$ for all $t \geq 0$. If $x \notin\left[0, \frac{1}{\delta}\right]$ or $y \notin\left[0, \frac{1}{\delta}\right]$, then an easy calculation shows us that $\alpha_{*}(T x, T y)=0$. If $0 \leq x, y \leq \frac{1}{\delta}$, then $\alpha_{*}(T x, T y)=1$. By using the definition of the Hausdorff metric, it is easy to see that $H(T x, T y) \leq \delta d(x, y)$ for $x, y \in\left[0, \frac{1}{\delta}\right]$. Thus, $\alpha_{*}(T x, T y) H(T x, T y) \leq \psi(d(x, y))$ for $x, y \in X$. Therefore, $T$ is an $\alpha_{*}-\psi$-contractive multifunction.

Let $(X, \preceq, d)$ be an ordered metric space and $A, B \subseteq X$. We say that $A \preceq B$ whenever for each $a \in A$ there exists $b \in B$ such that $a \preceq b$. Also, we say that $A \preceq_{r} B$ whenever for each $a \in A$ and $b \in B$ we have $a \preceq b$.

\section{Main results}

Now, we are ready to state and prove our main results. In the following result, we use the argument similar to that in the proof of Theorem 3.1 in [22].

Theorem 2.1 Let $(X, d)$ be a complete metric space, $\alpha: X \times X \rightarrow[0, \infty)$ be a function, $\psi \in \Psi$ be a strictly increasing map and $T$ be a closed-valued, $\alpha_{*}$-admissible and $\alpha_{*}-\psi$-contractive multifunction on $X$. Suppose that there exist $x_{0} \in X$ and $x_{1} \in T x_{0}$ such that $\alpha\left(x_{0}, x_{1}\right) \geq 1$. Assume that if $\left\{x_{n}\right\}$ is a sequence in $X$ such that $\alpha\left(x_{n}, x_{n+1}\right) \geq 1$ for all $n$ and $x_{n} \rightarrow x$, then $\alpha\left(x_{n}, x\right) \geq 1$ for all $n$. Then $T$ has a fixed point.

Proof If $x_{1}=x_{0}$, then we have nothing to prove. Let $x_{1} \neq x_{0}$. If $x_{1} \in T x_{1}$, then $x_{1}$ is a fixed point of $T$. Let $x_{1} \notin T x_{1}$ and $q>1$ be given. Then

$$
0<d\left(x_{1}, T x_{1}\right) \leq \alpha_{*}\left(T x_{0}, T x_{1}\right) H\left(T x_{0}, T x_{1}\right)<q \alpha_{*}\left(T x_{0}, T x_{1}\right) H\left(T x_{0}, T x_{1}\right) .
$$

Hence, there exists $x_{2} \in T x_{1}$ such that

$$
0<d\left(x_{1}, x_{2}\right)<q \alpha_{*}\left(T x_{0}, T x_{1}\right) H\left(T x_{0}, T x_{1}\right) \leq q \psi\left(d\left(x_{0}, x_{1}\right)\right) .
$$

It is clear that $x_{2} \neq x_{1}$ and $\alpha\left(x_{1}, x_{2}\right) \geq 1$. Thus, $\alpha_{*}\left(T x_{1}, T x_{2}\right) \geq 1$. Now, put $t_{0}=d\left(x_{0}, x_{1}\right)$. Then, $t_{0}>0$ and $d\left(x_{1}, x_{2}\right)<q \psi\left(t_{0}\right)$. Since $\psi$ is strictly increasing, $\psi\left(d\left(x_{1}, x_{2}\right)\right)<\psi\left(q \psi\left(t_{0}\right)\right)$. Put $q_{1}=\frac{\psi\left(q \psi\left(t_{0}\right)\right)}{\psi\left(d\left(x_{1}, x_{2}\right)\right)}$. Then $q_{1}>1$. If $x_{2} \in T x_{2}$, then $x_{2}$ is a fixed point of $T$. Assume that $x_{2} \notin T x_{2}$. Then

$$
0<d\left(x_{2}, T x_{2}\right) \leq \alpha_{*}\left(T x_{1}, T x_{2}\right) H\left(T x_{1}, T x_{2}\right)<q_{1} \alpha_{*}\left(T x_{1}, T x_{2}\right) H\left(T x_{1}, T x_{2}\right) .
$$

Hence, there exists $x_{3} \in T x_{2}$ such that

$$
0<d\left(x_{2}, x_{3}\right)<q_{1} \alpha_{*}\left(T x_{1}, T x_{2}\right) H\left(T x_{1}, T x_{2}\right) \leq q_{1} \psi\left(d\left(x_{1}, x_{2}\right)\right)=\psi\left(q \psi\left(t_{0}\right)\right) .
$$


It is clear that $x_{3} \neq x_{2}, \alpha\left(x_{2}, x_{3}\right) \geq 1$ and $\psi\left(d\left(x_{2}, x_{3}\right)\right)<\psi^{2}\left(q \psi\left(t_{0}\right)\right)$. Now, put $q_{2}=\frac{\psi^{2}\left(q \psi\left(t_{0}\right)\right)}{\psi\left(d\left(x_{2}, x_{3}\right)\right)}$. Then $q_{2}>1$. If $x_{3} \in T x_{3}$, then $x_{3}$ is a fixed point of $T$. Assume that $x_{3} \notin T x_{3}$. Then

$$
0<d\left(x_{3}, T x_{3}\right) \leq \alpha_{*}\left(T x_{2}, T x_{3}\right) H\left(T x_{2}, T x_{3}\right)<q_{2} \alpha_{*}\left(T x_{2}, T x_{3}\right) H\left(T x_{2}, T x_{3}\right) .
$$

Thus, there exists $x_{4} \in T x_{3}$ such that

$$
0<d\left(x_{3}, x_{4}\right)<q_{1} \alpha_{*}\left(T x_{2}, T x_{3}\right) H\left(T x_{2}, T x_{3}\right) \leq q_{2} \psi\left(d\left(x_{2}, x_{3}\right)\right)=\psi^{2}\left(q \psi\left(t_{0}\right)\right) .
$$

By continuing this process, we obtain a sequence $\left\{x_{n}\right\}$ in $X$ such that $x_{n} \in T x_{n-1}, x_{n} \neq x_{n-1}$, $\alpha\left(x_{n}, x_{n+1}\right) \geq 1$ and $d\left(x_{n}, x_{n+1}\right) \leq \psi^{n-1}\left(q \psi\left(t_{0}\right)\right)$ for all $n$. Now, for each $m>n$, we have

$$
d\left(x_{n}, x_{m}\right) \leq \sum_{i=n}^{m-1} d\left(x_{i}, x_{i+1}\right) \leq \sum_{i=n}^{m-1} \psi^{i-1}\left(q \psi\left(t_{0}\right)\right)
$$

Hence, $\left\{x_{n}\right\}$ is a Cauchy sequence in $X$. Choose $x^{*} \in X$ such that $x_{n} \rightarrow x^{*}$. Since $\alpha\left(x_{n}, x^{*}\right) \geq$ 1 for all $n$ and $T$ is $\alpha_{*}$-admissible, $\alpha_{*}\left(T x_{n}, T x^{*}\right) \geq 1$ for all $n$, thus

$$
\begin{aligned}
d\left(x^{*}, T x^{*}\right) & \leq H\left(T x^{*}, T x_{n}\right)+d\left(x_{n+1}, x^{*}\right) \leq \alpha_{*}\left(T x_{n}, T x^{*}\right) H\left(T x_{n}, T x^{*}\right)+d\left(x_{n+1}, x^{*}\right) \\
& \leq \psi\left(d\left(x_{n}, x^{*}\right)\right)+d\left(x_{n+1}, x^{*}\right)
\end{aligned}
$$

for all $n$. Therefore, $d\left(x^{*}, T x^{*}\right)=0$ and so $x^{*} \in T x^{*}$.

Example 2.1 Let $X=[0, \infty)$ and $d(x, y)=|x-y|$. Define $T: X \rightarrow 2^{X}$ by $T x=\left[2 x-\frac{3}{2}, \infty\right)$ for all $x>1, T x=\left[0, \frac{x}{2}\right]$ for all $0 \leq x \leq 1$ and $\alpha: X \times X \rightarrow[0, \infty)$ by $\alpha(x, y)=1$ whenever $x, y \in[0,1]$ and $\alpha(x, y)=0$ whenever $x \notin[0,1]$ or $y \notin[0,1]$. Then it is easy to check that $T$ is an $\alpha_{*}$-admissible and $\alpha_{*}-\psi$-contractive multifunction, where $\psi(t)=\frac{t}{2}$ for all $t \geq 0$. Put $x_{0}=1$ and $x_{1}=\frac{1}{2}$. Then $\alpha\left(x_{0}, x_{1}\right) \geq 1$. Also, if $\left\{x_{n}\right\}$ is a sequence in $X$ such that $\alpha\left(x_{n}, x_{n+1}\right) \geq 1$ for all $n$ and $x_{n} \rightarrow x$, then $\alpha\left(x_{n}, x\right) \geq 1$ for all $n$. Note that $T$ has infinitely many fixed points.

Corollary 2.2 Let $(X, \preceq, d)$ be a complete ordered metric space, $\psi \in \Psi$ be a strictly increasing map and $T$ be a closed-valued multifunction on $X$ such that

$$
H(T x, T y) \leq \psi(d(x, y))
$$

for all $x, y \in X$ with $x \preceq y$. Suppose that there exists $x_{0} \in X$ and $x_{1} \in T x_{0}$ such that $x_{0} \preceq x_{1}$. Assume that if $\left\{x_{n}\right\}$ is a sequence in $X$ such that $x_{n} \preceq x_{n+1}$ for all $n$ and $x_{n} \rightarrow x$, then $x_{n} \preceq x$ for all $n$. If $x \preceq y$ implies $T x \preceq_{r} T y$, then $T$ has a fixed point.

Proof Define $\alpha: X \times X \rightarrow[0, \infty)$ by $\alpha(x, y)=1$ whenever $x \preceq y$ and $\alpha(x, y)=0$ whenever $x \npreceq y$. Since $x \preceq y$ implies $T x \preceq_{r} T y, \alpha(x, y)=1$ implies $\alpha_{*}(T x, T y)=1$. Thus, it is easy to check that $T$ is an $\alpha_{*}$-admissible and $\alpha_{*}-\psi$-contractive multifunction on $X$. Now, by using Theorem 2.1, $T$ has a fixed point.

Now, we prove the following result for self-maps. 
Theorem 2.3 Let $(X, d)$ be a complete metric space, $\alpha: X \times X \rightarrow[0, \infty)$ be a function, $\psi \in \Psi$ and $T$ be a self-map on $X$ such that $\alpha(x, y) d(T x, T y) \leq \psi(m(x, y))$ for all $x, y \in X$, where $m(x, y)=\max \left\{d(x, y), d(x, T x), d(y, T y), \frac{1}{2}[d(x, T y)+d(y, T x)]\right\}$. Suppose that $T$ is $\alpha$-admissible and there exists $x_{0} \in X$ such that $\alpha\left(x_{0}, T x_{0}\right) \geq 1$. Assume that if $\left\{x_{n}\right\}$ is a sequence in $X$ such that $\alpha\left(x_{n}, x_{n+1}\right) \geq 1$ for all $n$ and $x_{n} \rightarrow x$, then $\alpha\left(x_{n}, x\right) \geq 1$ for all $n$. Then $T$ has a fixed point.

Proof Take $x_{0} \in X$ such that $\alpha\left(x_{0}, T x_{0}\right) \geq 1$ and define the sequence $\left\{x_{n}\right\}$ in $X$ by $x_{n+1}=T x_{n}$ for all $n \geq 0$. If $x_{n}=x_{n+1}$ for some $n$, then $x^{*}=x_{n}$ is a fixed point of $T$. Assume that $x_{n} \neq x_{n+1}$ for all $n$. Since $T$ is $\alpha$-admissible, it is easy to check that $\alpha\left(x_{n}, x_{n+1}\right) \geq 1$ for all natural numbers $n$. Thus, for each natural number $n$, we have

$$
\begin{aligned}
d\left(x_{n}, x_{n+1}\right) & =d\left(T x_{n-1}, T x_{n}\right) \leq \alpha\left(x_{n-1}, x_{n}\right) d\left(T x_{n-1}, T x_{n}\right) \\
& \leq \psi\left(\max \left\{d\left(x_{n}, x_{n-1}\right), d\left(x_{n}, x_{n+1}\right), d\left(x_{n-1}, x_{n}\right), \frac{1}{2}\left[d\left(x_{n}, x_{n}\right)+d\left(x_{n-1}, x_{n+1}\right)\right]\right\}\right) \\
& \leq \psi\left(\max \left\{d\left(x_{n}, x_{n-1}\right), d\left(x_{n}, x_{n+1}\right), \frac{1}{2}\left[d\left(x_{n}, x_{n-1}\right)+d\left(x_{n}, x_{n+1}\right)\right]\right\}\right) \\
& =\psi\left(\max \left\{d\left(x_{n}, x_{n-1}\right), d\left(x_{n}, x_{n+1}\right)\right\}\right) .
\end{aligned}
$$

If $\max \left\{d\left(x_{n}, x_{n-1}\right), d\left(x_{n}, x_{n+1}\right)\right\}=d\left(x_{n}, x_{n+1}\right)$, then

$$
d\left(x_{n+1}, x_{n}\right) \leq \psi\left(d\left(x_{n}, x_{n+1}\right)\right)<d\left(x_{n+1}, x_{n}\right)
$$

which is contradiction. Thus, $\max \left\{d\left(x_{n}, x_{n-1}\right), d\left(x_{n}, x_{n-1}\right)\right\}=d\left(x_{n}, x_{n+1}\right)$ for all $n$. Hence, $d\left(x_{n+1}, x_{n}\right) \leq \psi\left(d\left(x_{n}, x_{n-1}\right)\right)$ and so $d\left(x_{n+1}, x_{n}\right) \leq \psi^{n}\left(d\left(x_{1}, x_{0}\right)\right)$ for all $n$. It is easy to check that $\left\{x_{n}\right\}$ is a Cauchy sequence. Thus, there exists $x^{*} \in X$ such that $x_{n} \rightarrow x^{*}$. By using the assumption, we have $\alpha\left(x_{n}, x^{*}\right) \geq 1$ for all $n$. Thus,

$$
\begin{aligned}
d\left(T x^{*}, x^{*}\right) \leq & d\left(T x^{*}, T x_{n}\right)+d\left(x_{n+1}, x^{*}\right) \leq \alpha\left(x_{n}, x^{*}\right) d\left(T x^{*}, T x_{n}\right)+d\left(x_{n+1}, x^{*}\right) \\
\leq & \psi\left(\operatorname { m a x } \left\{d\left(x_{n}, x^{*}\right), d\left(x_{n}, x_{n+1}\right), d\left(x^{*}, T x^{*}\right),\right.\right. \\
& \left.\left.\frac{1}{2}\left[d\left(x_{n}, T x^{*}\right)+d\left(x^{*}, x_{n+1}\right)\right]\right\}\right)+d\left(x_{n+1}, x^{*}\right) \\
\leq & \psi\left(d\left(x^{*}, T x^{*}\right)\right)+d\left(x_{n+1}, x^{*}\right)
\end{aligned}
$$

for sufficiently large $n$. Hence, $d\left(T x^{*}, x^{*}\right)=0$ and so $T x^{*}=x^{*}$.

Example 2.2 Let $X=[0, \infty)$ and $d(x, y)=|x-y|$. Define the self-map $T$ on $X$ by $T x=$ $2 x-\frac{5}{3}$ for $x>1, T x=\frac{x}{3}$ for $0 \leq x \leq 1$ and $\alpha: X \times X \rightarrow[0, \infty)$ by $\alpha(x, y)=1$ whenever $x, y \in[0,1]$ and $\alpha(x, y)=0$ whenever $x \notin[0,1]$ or $y \notin[0,1]$. Then it is easy to check that $T$ is $\alpha$-admissible and $\alpha(x, y) d(T x, T y) \leq \psi(m(x, y))$ for all $x, y \in X$, where $\psi(t)=\frac{t}{3}$ for all $t \geq 0$. Also, $\alpha(1, T 1)=1$ and if $\left\{x_{n}\right\}$ is a sequence in $X$ such that $\alpha\left(x_{n}, x_{n+1}\right) \geq 1$ for all $n$ and $x_{n} \rightarrow x$, then $\alpha\left(x_{n}, x\right) \geq 1$ for all $n$. Note that, $T$ has two fixed points.

Corollary 2.4 Let $(X, \preceq, d)$ be a complete ordered metric space, $\psi \in \Psi$ and $T$ be a selfmap on $X$ such that $d(T x, T y) \leq \psi(m(x, y))$ for all $x, y \in X$ with $x \preceq y$. Suppose that there 
exists $x_{0} \in X$ such that $x_{0} \preceq T x_{0}$. If $\left\{x_{n}\right\}$ is a sequence in $X$ such that $x_{n} \preceq x_{n+1}$ for all $n$ and $x_{n} \rightarrow x$, then $x_{n} \preceq x$ for all $n$. If $x \preceq y$ implies $T x \preceq T y$, then $T$ has a fixed point.

If we substitute a partial metric $\rho$ for the metric $d$ in Theorem 2.3, it is easy to check that a similar result holds for the partial metric case as follows.

Theorem 2.5 Let $(X, \rho)$ be a complete partial metric space, $\alpha: X \times X \rightarrow[0, \infty)$ be a function, $\psi \in \Psi$ and $T$ be a self-map on $X$ such that $\alpha(x, y) \rho(T x, T y) \leq \psi(m(x, y))$ for all $x, y \in X$, where $m(x, y)=\max \left\{\rho(x, y), \rho(x, T x), \rho(y, T y), \frac{1}{2}[\rho(x, T y)+\rho(y, T x)]\right\}$. Suppose that $T$ is $\alpha$-admissible and there exists $x_{0} \in X$ such that $\alpha\left(x_{0}, T x_{0}\right) \geq 1$. Assume that if $\left\{x_{n}\right\}$ is a sequence in $X$ such that $\alpha\left(x_{n}, x_{n+1}\right) \geq 1$ for all $n$ and $x_{n} \rightarrow x$, then $\alpha\left(x_{n}, x\right) \geq 1$ for all $n$. Then $T$ has a fixed point.

Competing interests
The authors declare that they have no competing interests.

Authors' contributions

All authors contributed equally and significantly in writing this article. All authors read and approved the final manuscript.

Author details

'Department of Mathematics, Science and Research Branch, Islamic Azad University, Tehran, Iran. ${ }^{2}$ Department of Mathematics, Azarbaijan Shahid Madani University, Tabriz, Azarshahr, Iran. ${ }^{3}$ Department of Mathematics, King Abdulaziz University, P.O. Box 80203, Jeddah, 21859, Saudi Arabia.

\section{Acknowledgements}

The authors are grateful to the reviewers for their useful comments.

Received: 5 May 2012 Accepted: 26 October 2012 Published: 26 November 2012

\section{References}

1. Abbas, M, Nazir, T, Radenovic, S: Common fixed points of four maps in partially ordered metric spaces. Appl. Math. Lett. 24, 1520-1526 (2011)

2. Aleomraninejad, SMA, Rezapour, S, Shahzad, N: On generalizations of the Suzuki's method. Appl. Math. Lett. 24, 1037-1040 (2011)

3. Aleomraninejad, SMA, Rezapour, S, Shahzad, N: Fixed points of hemi-convex multifunctions. Topol. Methods Nonlinear Anal. 37(2), 383-389 (2011)

4. Aleomraninejad, SMA, Rezapour, S, Shahzad, N: Some fixed point results on a metric space with a graph. Topol. Appl. $159,659-663(2012)$

5. Alghamdi, MA, Alnafei, SH, Radenovic, S, Shahzad, N: Fixed point theorems for convex contraction mappings on cone metric spaces. Math. Comput. Model. 54, 2020-2026 (2011)

6. Altun, I, Damjanovic, B, Djoric, D: Fixed point and common fixed point theorems on ordered cone metric spaces. Appl. Math. Lett. 23, 310-316 (2010)

7. Aydi, H, Damjanovic, B, Samet, B, Shatanawi, W: Coupled fixed point theorems for nonlinear contractions in partially ordered G-metric spaces. Math. Comput. Model. 54, 2443-2450 (2011)

8. Aydi, H, Nashine, HK, Samet, B, Yazidi, H: Coincidence and common fixed point results in partially ordered cone metric spaces and applications to integral equations. Nonlinear Anal. 74, 6814-6825 (2011)

9. Berinde, V: Generalized coupled fixed point theorems for mixed monotone mappings in partially ordered metric spaces. Nonlinear Anal. 74, 7347-7355 (2011)

10. Berinde, $V$, Borcut, $M$ : Tripled fixed point theorems for contractive type mappings in partially ordered metric spaces. Nonlinear Anal. 74, 4889-4897 (2011)

11. Berinde, $V$, Vetro, F: Common fixed points of mappings satisfying implicit contractive conditions. Fixed Point Theory Appl. 2012, 105 (2012)

12. Borcut, $\mathrm{M}$, Berinde, $\mathrm{V}$ : Tripled coincidence theorems for contractive type mappings in partially ordered metric spaces. Appl. Math. Comput. (2012). doi:10.1016/j.amc.2011.11.049

13. Derafshpour, M, Rezapour, S, Shahzad, N: Best proximity points of cyclic $\varphi$-contractions in ordered metric spaces Topol. Methods Nonlinear Anal. 37, 193-202 (2011)

14. Di Bari, C, Vetro, P: Fixed points for weak $\varphi$-contractions on partial metric spaces. Int. J. Eng. Contemp. Math. Sci. 1, 4-9 (2011)

15. Di Bari, C, Vetro, P: $\varphi$-pairs and common fixed points in cone metric spaces. Rend. Circ. Mat. Palermo 57, 279-285 (2008) doi:10.1007/s12215-008-0020-9

16. Di Bari, C, Vetro, P: Weakly $\varphi$-pairs and common fixed points in cone metric spaces. Rend. Circ. Mat. Palermo 58, 125-132 (2009). doi:10.1007/s12215-009-0012-4

17. Ding, HS, Lu, L: Coupled fixed point theorems in partially ordered cone metric spaces. Filomat 25(2), 137-149 (2011) 
18. Du, W-S: Coupled fixed point theorems for nonlinear contractions satisfied Mizoguchi-Takahashi's condition in quasi-ordered metric spaces. Fixed Point Theory Appl. 2010, Article ID 876372 (2010)

19. Haghi, RH, Rezapour, S, Shahzad, N: Some fixed point generalizations are not real generalizations. Nonlinear Anal. 74, 1799-1803 (2011)

20. Hu, X-Q, Ma, X-Y: Coupled coincidence point theorems under contractive conditions in partially ordered probabilistic metric spaces. Nonlinear Anal. 74, 6451-6458 (2011)

21. Jachymski, J: Equivalent conditions for generalized contractions on (ordered) metric spaces. Nonlinear Anal. 74 , 768-774 (2011)

22. Lazar, VL: Fixed point theory for multivalued $\phi$-contractions. Fixed Point Theory Appl. 2011,50 (2011)

23. Luong, NV, Thuan, NX: Coupled fixed points in partially ordered metric spaces and application. Nonlinear Anal. 74, 983-992 (2011)

24. Nashine, HK, Samet, B, Vetro, C: Monotone generalized nonlinear contractions and fixed point theorems in ordered metric spaces. Math. Comput. Model. 54, 712-720 (2011)

25. Nashine, HK, Samet, B: Fixed point results for mappings satisfying $(\psi, \varphi)$-weakly contractive condition in partially ordered metric spaces. Nonlinear Anal. 74, 2201-2209 (2011)

26. Nashine, HK, Shatanawi, W: Coupled common fixed point theorems for a pair of commuting mappings in partially ordered complete metric spaces. Comput. Math. Appl. 62, 1984-1993 (2011)

27. Rezapour, S, Amiri, P: Some fixed point results for multivalued operators in generalized metric spaces. Comput. Math. Appl. 61, 2661-2666 (2011)

28. Rezapour, S, Haghi, RH: Some notes on the paper 'Cone metric spaces and fixed point theorems of contractive mappings'. J. Math. Anal. Appl. 345, 719-724 (2008)

29. Rezapour, S, Haghi, RH, Rhoades, BE: Some results about $T$-stability and almost $T$-stability. Fixed Point Theory 12(1), 179-186 (2011)

30. Rezapour, S, Haghi, RH, Shahzad, N: Some notes on fixed points of quasi-contraction maps. Appl. Math. Lett. 23 498-502 (2010)

31. Rus, MD: Fixed point theorems for generalized contractions in partially ordered metric spaces with semi-monotone metric. Nonlinear Anal. 74, 1804-1813 (2011)

32. Samet, B, Vetro, C: Coupled fixed point theorems for multi-valued nonlinear contraction mappings in partially ordered metric spaces. Nonlinear Anal. 74, 4260-4268 (2011)

33. Samet, B, Vetro, C, Vetro, P: Fixed point theorems for $\alpha$ - $\psi$-contractive type mappings. Nonlinear Anal. 75, $2154-2165$ (2012)

34. Shatanawi, W, Samet, B: On $(\psi, \varphi)$-weakly contractive condition in partially ordered metric spaces. Comput. Math Appl. 62, 3204-3214 (2011)

35. Vetro, F: On approximating curves associated with nonexpansive mappings. Carpath. J. Math. 27, 142-147 (2011)

36. Vetro, P: Common fixed points in cone metric spaces. Rend. Circ. Mat. Palermo 56, 464-468 (2007). doi:10.1007/BF03032097

37. Zhang, X: Fixed point theorems of multivalued monotone mappings in ordered metric spaces. Appl. Math. Lett. 23 235-240 (2010)

38. Zhilong, L: Fixed point theorems in partially ordered complete metric spaces. Math. Comput. Model. 54, 69-72 (2011)

doi:10.1186/1687-1812-2012-212

Cite this article as: Asl et al.: On fixed points of $\alpha-\psi$-contractive multifunctions. Fixed Point Theory and Applications 2012 2012:212

\section{Submit your manuscript to a SpringerOpen ${ }^{\circ}$ journal and benefit from:}

- Convenient online submission

- Rigorous peer review

- Immediate publication on acceptance

- Open access: articles freely available online

- High visibility within the field

- Retaining the copyright to your article 